\title{
Observations of a phytoplankton spring bloom onset triggered by a density front in NW Mediterranean
}

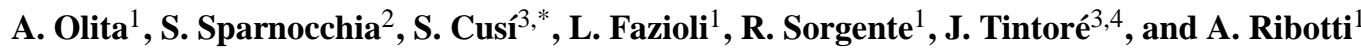 \\ ${ }^{1}$ SOCIB, Balearic Islands Coastal Observing and Forecasting System, Palma de Mallorca, Spain \\ ${ }^{2}$ CNR-ISMAR, Institute of Marine Sciences, Trieste Section, Trieste, Italy \\ ${ }^{3}$ SOCIB, Balearic Islands Coastal Observing and Forecasting System, Palma de Mallorca, Spain \\ ${ }^{4}$ IMEDEA (CSIC-UiB), Esporles, Spain \\ *now at: CSIC-UTM, Marine Technology Unit, Barcelona, Spain
}

Correspondence to: A. Olita (antonio.olita@cnr.it)

Received: 5 August 2013 - Published in Ocean Sci. Discuss.: 11 September 2013

Revised: 12 June 2014 - Accepted: 18 June 2014 - Published: 14 July 2014

\begin{abstract}
Phytoplankton blooms in the northwestern Mediterranean Sea are seasonal events that mainly occur in a specific area comprising the Gulf of Lion and the Provençal basin, where they are promoted by a general cyclonic circulation, strong wind-driven mixing and subsequent re-stratification of the water column. At the southern boundary of this area, a persistent density front known as the north Balearic front can be found. The front is presumed to cause an early phytoplankton bloom in its vicinity because (a) it enhances the transport of nutrients into the euphotic layer and (b) it promotes the speedy re-stratification of the water column (through frontal instabilities). In February and March 2013, a glider, equipped with a CTD (conductivity, temperature, and depth device) and a fluorometer, was deployed on a mission that took it from the Balearic Islands to Sardinia and back. The frontal zone was crossed twice, once during the outbound leg and the once on the return leg. The data provided by the glider clearly showed the onset of a bloom soon after a decrease in wind-driven turbulent convection and mixing. The in situ observations were supported and confirmed by satellite imagery. It is shown that frontal dynamics play a key role in the promotion and acceleration of re-stratification, which is a necessary preconditioning factor for the onset of blooms much like other relevant processes such as an enhanced biological pump. Swift re-stratification stimulates new production by inhibiting mixing. Finally, viewing the blooming phenomenon from a regional perspective, it seems that Sverdrup's critical depth
\end{abstract}

model applies in the northern well-mixed area whereas, in the south, front-related re-stratification seems to be the principal cause.

\section{Introduction}

A debate is underway in the oceanographic community concerning the physical/ecological mechanisms that trigger the seasonal phytoplankton bloom in seas and oceans. Some authors (Huisman et al., 1999; Behrenfeld, 2010; Taylor and Ferrari, 2011b; Martin, 2012) have recently questioned the validity of the classical critical depth (CD) hypothesis (Sverdrup, 1953) used to explain the phenomenon, which was formulated for conditions on the global or basin scale. The CD hypothesis states that when the mixed layer (ML) depth is shallower than the CD, assuming favourable environmental conditions (light is not a limiting factor, and loss $<$ growth), blooms are triggered and maintained thanks to the residence, persistence and growth of phytoplanktonic populations in the euphotic layer. The CD model assumes a vertically homogeneous distribution of phytoplankton in the water column, a situation which could be considered true perhaps only for well-mixed layers. Chiswell (2011), in fact, showed that the model cannot be applied in spring because of the uneven plankton distribution in the ML, but stated that it should not be abandoned completely because of its serviceability under well-mixed conditions such as those 
encountered in autumn/winter. Behrenfeld (2010), on the basis of satellite imagery and in situ biomass records in the North Atlantic, openly contested the CD hypothesis, instead postulating a dilution-recoupling (DR) process hinging on the balance between growth and mainly grazing-related loss. On the other hand, Taylor and Ferrari (2011b), extending the work of Huisman et al. (1999) which first contraposed the concept of critical turbulence (CT) to the CD explanation, found that while the primary driver is the atmospheric forcing (the turnoff of the wind forcing, to be exact) like in the Sverdrup paradigm, the regulating factor is the reduction of vertical turbulence (vertical convection) and not the shoaling of the ML. It should be underlined that Taylor and Ferrari (2011b) focused their attention on the turbulence generated by surface cooling, and therefore to the convection driven by heat fluxes. The contribution of momentum to the turbulence was not investigated, although it could be important to round out the CT argument. The results of Bernardello et al. (2012) also support the CT premise. Examining an area of the northwestern Mediterranean Sea characterized by deep mixing and a strong seasonal bloom through a coupled physicalbiological model, they found that the reduction of heat fluxes was a better predictor of bloom onset than the shallowing of the ML. Regardless of the determinant governing the timing and strength of bloom onsets, be it CD, DR or CT, the rationale behind the different hypotheses is quite similar in that the essential condition to be met is the persistence of phytoplanktonic cells in the euphotic layer operated by physical processes. Frontal systems are a particularly apt setting to examine this assertion in greater detail.

Fronts are well known for their high productivity, at both the mesoscale and sub-mesoscale. Taylor and Ferrari (2011a), in a paper on the role of fronts in primary production in high-latitude regions, showed that frontal re-stratification inhibits vertical mixing, and favours blooming. Weakened mixing reduces the flux of phytoplankton cells out of the euphotic zone. This could be a relevant process in oligotrophic regions at mid-latitudes too. There is also evidence (Rodríguez et al., 2001; Lévy et al., 2001; Mahadevan and Tandon, 2006; Lévy, 2008) that submesoscale cyclones and density fronts can promote primary production by increasing the upwelling of nutrients into the photic layers by virtue of the very large vertical velocities they tend to generate. Mahadevan et al. (2012) have shown that, at high latitudes in the North Atlantic, the stratification required for triggering a bloom is often not initiated by the seasonal warming but by eddy instabilities in areas of strong density gradients. Such instabilities, in the absence of strong wind forcing, cause lighter water to stratify over denser water even when heating is nonexistent. The same process, induced by frontal instabilities of the southward flowing boundary current along the shelf-break topography, was shown to promote enhanced winter phytoplankton production within the Catalan-Balearic Sea (Oguz et al., 2014), i.e. the area enclosed between the Spanish coast and
Balearic Islands. Neglecting the specificities of the features that were handled (eddy vs. front), what is interesting is that the underlying mechanism described by the authors is similar to the one proposed for high latitude fronts. Lévy et al. (2012), in their review on the sub-mesoscale and blooms, note that, from the observational perspective, there now exist oceanographic instruments like gliders and other autonomous underwater vehicles (AUVs) capable of resolving sub-mesoscale processes even under critical environmental conditions.

This work presents the results from a glider survey that was carried out to investigate the impact of mixing and restratification on the triggering of the seasonal bloom in the central part of the Algero-Provençal basin (northwestern Mediterranean Sea) in the area of the north Balearic front (hereafter referred to as NBF). The main aim was actually to understand the role of the front in the bloom triggering. The survey was conducted within the framework of the transnational activity (TNA) programme of the EU-FP7 JERICO (Towards a Joint European Research Infrastructure network for Coastal Observatories) project, part of the activities of the Balearic Islands Coastal Observing and Forecasting System (SOCIB) glider facilities (Tintoré et al., 2013). The glider was sent on a round trip from the Balearic Islands to Sardinia and back (Fig. 1) in the February and March period of 2013, the most favourable period of the year for the onset of the seasonal bloom in the NBF area. The hydrological and fluorometric observations it provided were complemented by relevant satellite ocean colour images and auxiliary modelled data to study the relative relevance of vertical mixing, heat fluxes, stratification and ML depth on bloom timing and strength.

\section{Materials, methods and data}

\subsection{Glider description, settings and data}

The glider used in the experiment was a $1 \mathrm{KA}$ Seaglider ${ }^{\mathrm{TM}}$ (Eriksen et al., 2001) manufactured by iRobot. Basically, this glider moves through the water by means of a buoyancy engine which is used to alter the vehicle overall density, causing it to sink or rise vertically. The wings on the glider translate the vertical displacement into forward motion. The result is the characteristic sawtooth navigation pattern common to this kind of vehicle. The main battery pack, weighing approximately $10 \mathrm{~kg}(20 \%$ of the total weight of the glider), can be shifted inside the housing to modify pitch, roll and heading. The glider navigates by dead reckoning to programmed waypoints, inflecting at set depths and altitudes based on the coordinates and parameters supplied to it in a specific mission text file. As set by the mission, it periodically surfaces to communicate data and instructions, and to obtain a GPS fix for location. Any difference in dead reckoning and position is attributed to current, and that knowledge is 


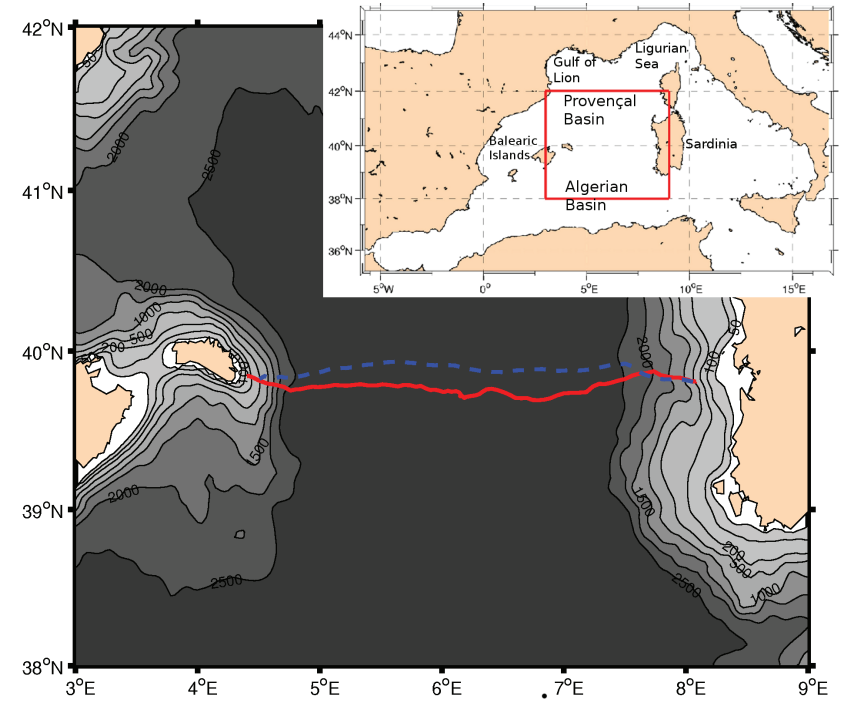

Figure 1. The route of the glider superimposed on the bathymetry in the studied area. Both outbound (west-to-east, red line) and return (east-to-west, blue line) tracks are shown. The bathymetry has been extracted from the US Navy Digital Bathymetric Data Base $\left(1 / 60^{\circ}\right.$ of resolution).

used on the subsequent segment. Navigational aids include a GPS receiver, a compass, a pressure sensor, and a transponder for bottom detection. For the mission in the NBF area, the Seaglider was configured to dive and climb at a velocity of about $10 \mathrm{~cm} \mathrm{~s}^{-1}$, equivalent to a horizontal headway of roughly $17 \mathrm{~cm} \mathrm{~s}^{-1}$, without taking currents into account. The pitch angle was about 20 degrees and the maximum operating depth range, bathymetry permitting, was $0-1000 \mathrm{~m}$. A free-flushed Sea-Bird CT Sail (S/N 0173), last calibrated in March 2011, provided conductivity $(C)$ and temperature $(T)$ measurements, and a Paine Electronics pressure sensor (S/N 264065) calibrated in February 2011 was used to obtain depth $(D)$ readings. The glider acquired CTD (conductivity, temperature, and depth device) data once every $4.6 \mathrm{~s}$ (approximately once every $0.46 \mathrm{~m}$ along its trajectory), down to a depth of $1000 \mathrm{~m}$. The data were post-processed using the University of Washington's Python routines for computing conductivity, temperature, salinity, and potential density from raw readings. The usual instrumental lags influencing glider CTD data were handled employing the Glider Matlab Toolbox described by Garau et al. (2011) and available at http://socib.es/users/glider/glider_toolbox/. In particular, as an unpumped CTD was used, the data were affected by a thermal lag which had to be corrected. Salinity and temperature profiles were divided into two groups, one for the outbound leg and another for the return one to simplify analysis and interpretation. Both ascending and descending profiles were used. Densities were interpolated on a regular grid having a horizontal and vertical resolution of about $2 \mathrm{~km}$ and $1 \mathrm{~m}$, respectively, in order to better assess the ML depth.
The ML depth was estimated along both the west-to-east and the east-to-west transects using a threshold method: the lower limit of the ML at any location was identified as a density increase greater than $0.2 \mathrm{~kg} \mathrm{~m}^{-3}$ with respect to the (sub-)surface value. The method assumes that the mean density at the computed ML depth will not exceed an arbitrary threshold $\left(28.8 \mathrm{~kg} \mathrm{~m}^{-3}-1000\right)$. Should this happen, what could be indicated is the presence of waters upwelled to the surface, and the real ML depth would be close to zero. In this kind of situation, the algorithm fails to supply a viable solution. Apart from the mentioned CTD sensors, the glider was also equipped with a WET Labs ECO Triplet fluorometer (S/N BBFL2VMT-777) capable of measuring fluorescence and furnishing derived chlorophyll $a$ values. The instrument, with a declared resolution of $0.012 \mu \mathrm{g} \mathrm{L}^{-1}$ for chlorophyll $a$, was calibrated in November 2010 by the manufacturer. During the first week of the survey, the fluorometer was active in the first $300 \mathrm{~m}$ of the water column. From the second week onwards, its maximum sampling depth was reduced to $180 \mathrm{~m}$ to minimize energy consumption. Once the west-to-east section was completed, it was decided to use the fluorometer on every fourth dive only because the energy consumption continued to remain too high. The sampling rate of the instrument was roughly $9.2 \mathrm{~s}$ during the entire mission, which corresponds to one reading at $0.92 \mathrm{~m}$ intervals along the glider's path. Values for chlorophyll $a$ (hereafter referred to as $\mathrm{Chl} a$ ) were obtained from measured fluorescence using the relevant calibration information provided by the manufacturer. Fluorescence observations gathered during the day can sometimes be subject to errors caused by a reduction in yield related to insolation, the well-known quenching effect. However, the glider data set for the parameter did not show any substantial day-to-night differences, probably because of the period when the survey was conducted. There are reports in the literature Sackmann et al. (2008) that the quenching effect is quite small in winter.

\subsection{Satellite imagery and modelling}

The following additional sources of useful information were tapped to support the glider observations and aid in the interpretation of results.

Relevant $1 \mathrm{~km}$, Level-2 (single swaths) Ocean Color data, acquired by the MODerate resolution Imaging Spectroradiometer (MODIS) sensor aboard NASA's AQUA satellite, were downloaded from the Ocean Color web portal (http://oceancolor.gsfc.nasa.gov). Once transferred, the data were re-projected and mapped using the SEADAS ${ }^{\mathrm{TM}} 7.0$ software. The resulting data set was used to qualitatively evaluate the glider observations from a more synoptic perspective, which helped in their interpretation. Information on surface heat fluxes germane to the period of the glider deployment was obtained using the western Mediterranean regional model, which is the operational implementation of the Princeton Ocean Model (POM, Blumberg and Mellor, 1987) 
for the western Mediterranean Sea. The model provides daily 5-day forecasts of currents and other relevant ocean variables in the western Mediterranean (www.seaforecast.cnr.it). Heat fluxes were computed employing bulk formulae, following Castellari et al. (1998). We assume for the sake of convention that heat fluxes are positive when the sea surface is gaining heat. Wind stress data have also been extracted from the model outputs.

\section{Results}

The entire glider survey lasted about 40 days, from 31 January to 9 March 2013. Temperature and salinity $(S)$ sections comprising the first $600 \mathrm{~m}$ of the water column are presented for the outbound and return legs of the deployment in Fig. 2. Figure 3 shows the associated cumulative $\theta-S$ diagram, with the main water masses present labelled. What is notable at first glance is that the stratification in the area was very variable throughout. This is the typical signature of intense mesoscale activity. Alternating deep and shallow ML areas, with steep isosurfaces, suggest a succession of convergence and divergence zones emblematic of mesoscale instabilities (frontal meanders and eddies). During the outbound leg, the most evident feature is a large zone between $\sim 5$ and $\sim 6^{\circ} \mathrm{E}$ characterized by a deep and well-mixed upper layer between 100 and $150 \mathrm{~m}$ (see also the ML depth panel in Fig. 4). In this zone, the temperature was about $14.3^{\circ} \mathrm{C}$ and a relative salinity minimum of $\sim 37.8$ could be found, which indicates the presence of Modified Atlantic Water, MAW for short (e.g. Ribotti et al., 2004). The value encountered for the salinity minimum denotes an "old" MAW as it is quite higher than the values associated with similar minima near the Strait of Gibraltar where water from the Atlantic Ocean enters the Mediterranean basin. The Chl $a$ concentration was lower than $1 \mathrm{mg} \mathrm{m}^{-3}$ and uniform within the deep ML. MODIS images (Fig. 5) did not evidence any coherent mesoscale feature, so such deep mixing should be due to wind.

More to the east, at around $\sim 6.8^{\circ} \mathrm{E}$, another narrow tract, characterized by upwelled cold and salty waters, could be distinguished. This upwelling is due to the divergence generated by the proximity of two anticyclones, labelled A1 and A2 in the satellite image in the bottom panel of Fig. 5. Anticyclone $\mathrm{A} 1$ was located $\sim 6$ and $\sim 7^{\circ} \mathrm{E}$ and $\mathrm{A} 2$ lay between $\sim 7$ and $\sim 8^{\circ}$ E. Anticyclone A2 is well-defined during both legs, as evinced by the characteristic inverse-bell shape of the isolines, corresponding to a deepening of the ML in the area of its location in Fig. 2. Unlike A2, A1 is less obvious in the same figure, but its existence is apparent in the comparable behaviour of the isopycnals in Fig. 4. During the return leg, the vertical conformations of the two features, especially A1, were different (see Figs. 2 and 4). This change could be due to the meandering of the features themselves or the fact that the glider was unable to exactly retrace its outbound course while doubling back, or because of both these reasons.
Anticyclone A2 is quite evenly extensive in the section of the outbound leg. In the section of the return crossing, it appears to stretch more towards the Sardinian continental slope. This is probably an artifact arising from the characteristics of the data set for this leg: while returning, the glider traversed the feature only along its periphery. The Chl $a$ distribution along the section corroborates this conjecture. The core of the MAW ( $S<\sim 37.6)$ was confined to the western arm of A2 during the first leg; in the second leg, it was observable in the eastern arm also. As reported in the literature (Millot and Taupier-Letage, 2005; Heslop et al., 2012, among others), the core of the intermediate water mass of the Mediterranean, the Levantine Intermediate Water (LIW) is clearly identifiable $\left(\theta=14.3^{\circ} \mathrm{C}\right.$ and $\left.S=38.6-38.8\right)$ along the continental margin of western Sardinia between 300-600 m of depth in both legs (Fig. 2). The specific position of this core at any particular location is strongly affected by eddy activity. This is evident in Fig. 2 wherein the LIW core can be detected at $300-400 \mathrm{~m}$ in the first leg and at around $200 \mathrm{~m}$ in the second. Another LIW core (slightly modified with respect to the one mentioned above) is discernible in the middle of the transect of the first leg. Its presence is probably the result of the transport associated with an eddy (A2) that was not picked up in the glider observations but is visible in the satellite image in Fig. 5. This second LIW core is absent in the transect of the second leg, perhaps because of mixing with neighbouring waters or because the route taken by the returning glider missed it completely.

The previously cited deep ML found at the beginning of February had completely disappeared when the glider passed through the same area almost one month later on its return leg. In March, the warm core of the anticyclonic meander noted earlier had cooled considerably, assuming temperature values similar to those of the surrounding waters. The strong cooling was caused by some severe wind events (Fig. 7), and it resulted in an increase in surface water densities. This, however, did not generate a deeper ML because the underlying LIW, which is characterized by heavier and saltier waters, gave rise to a very persistent salinity-dominated stratification and uplifted isopycnals (Fig. 4). Thus, the ML was shallower in March than at the beginning of February despite the cooling and the thermal homogeneity of the water column. The distribution of Chl $a$ shows some response to the shoaling, although the overall $\mathrm{Chl} a$ concentrations never exceed $1 \mathrm{mg} \mathrm{m}^{-3}$. This is probably because the ML is still quite deep (70-90 m), biologically speaking, even if turbulent convection has already been reduced by the zeroing of surface heat fluxes (Fig. 7). At the extreme western end of the transect of the second leg (between $\sim 4.5$ and $\sim 5^{\circ} \mathrm{E}$ ), the ML depth rises to above $40 \mathrm{~m}$ due to a density increase that is greatest in the $40-120 \mathrm{~m}$ layer. The increase in density stems from the particular situation that was observed there earlier in February, when the water column was almost completely uniform from about $10 \mathrm{~m}$ below the surface to almost $120 \mathrm{~m}$. The shallow ML in March can be associated with a 

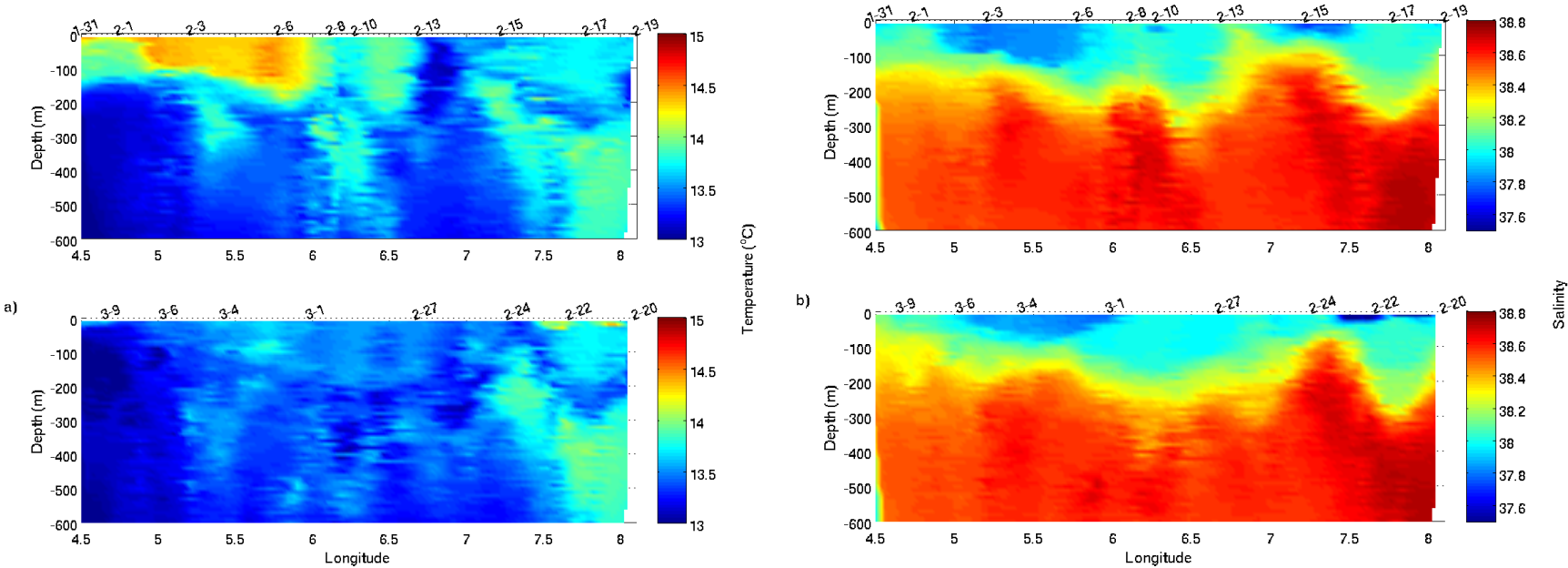

Figure 2. Zonal sections of (a) temperature and (b) salinity for the outbound (upper panels) and return (lower panels) legs of the glider mission.

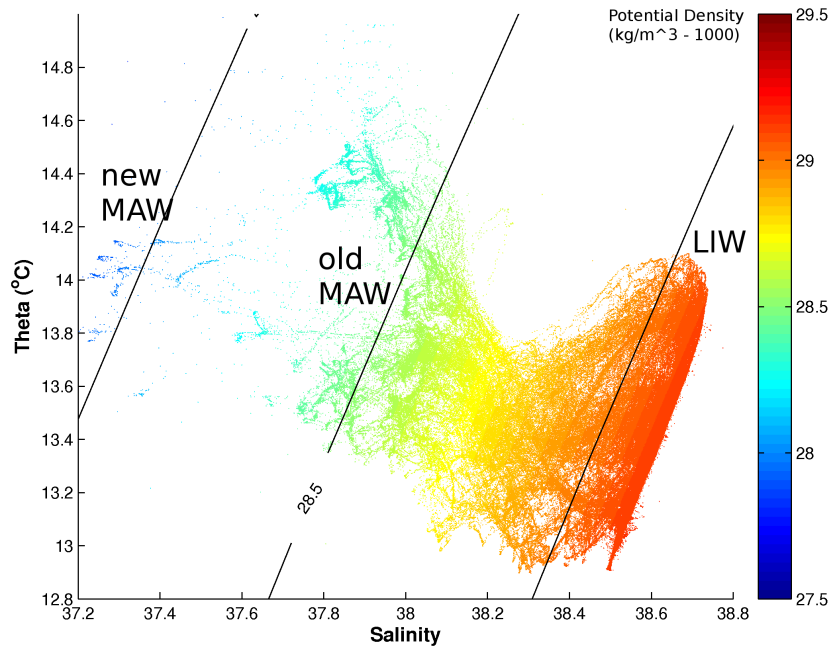

Figure 3. Cumulative $\theta-S$ diagram. LIW = the Levantine Intermediate Water; new MAW = the Modified Atlantic Water of more recent origin; old MAW = the Modified Atlantic Water reservoir of the Algerian sub-basin.

clear biological signal: the $\mathrm{Chl} a$ increases up to $2.5 \mathrm{mg} \mathrm{m}^{-3}$ in the frontal zone between $\sim 4.5$ and $\sim 5^{\circ} \mathrm{E}$. It is very likely that this is caused by the instabilities of the front itself: it is evident from satellite images that the area where the bloom begins is coincident with a frontal meander. According to Taylor and Ferrari (2011a), frontal instabilities promote the re-stratification of the water column when the wind forcing is low enough to weaken turbulent convection sufficiently. The maps of the Brunt-Väisälä (buoyancy) frequency presented in Fig. 4c serve to determine strongly stratified and well-mixed areas. The features visible in the maps reflect the established behaviour of the ML depth quite well. Indeed, the signs of increased surface stratification in the frontal zone (on the left side in the plots) during the second leg and the breakout of a deep thermal stratification are unmistakable. Figure 6 shows the behaviour of $\mathrm{Chl} a$, integrated over the first $100 \mathrm{~m}$ of the water column, for the outbound and return legs of the glider's journey. There does not seem to be any clear spatial or temporal low-frequency trend. However, evident deviations from the overall mean value can be noted, mainly due to the mesoscale activity described in the preceding paragraphs. The most evident high-frequency peak occurred at the end of the second leg when the surface bloom was triggered along the NBF: the value of integrated Chl $a$ was $>110 \mathrm{mg} \mathrm{m}^{-2}$, which is more than twice the mean value $\left(\sim 53 \mathrm{mg} \mathrm{m}^{-2}\right)$.

\section{Bloom triggering mechanism}

The biological response that follows the shoaling of the ML in the frontal zone begins a few days after the change of sign of the surface heat fluxes (Fig. 7), before the full thermal restratification of the upper layers. The winter cooling of the sea surface was interrupted at the beginning of March when the (cold) winds from the northwest stopped and a period of (warm) winds from the south. The heat fluxes inverted, and the area where the front prevailed started to re-stratify. The early re-stratification reduces the possibility of mixing of upper euphotic and underlying aphotic waters. The spatial/temporal pattern of the heat fluxes is similar to that of the well-studied MEDOC area (e.g., Auger et al., 2014) in the western Mediterranean (i.e., the Gulf of Lion and thereabouts). In the MEDOC area, however, the circulation is mainly cyclonic, and strong blooms are known to occur seasonally in concomitance with deep mixing, often after early blooming in the central and southern part of the western Mediterranean (Olita et al., 2011b). This was observed in the 

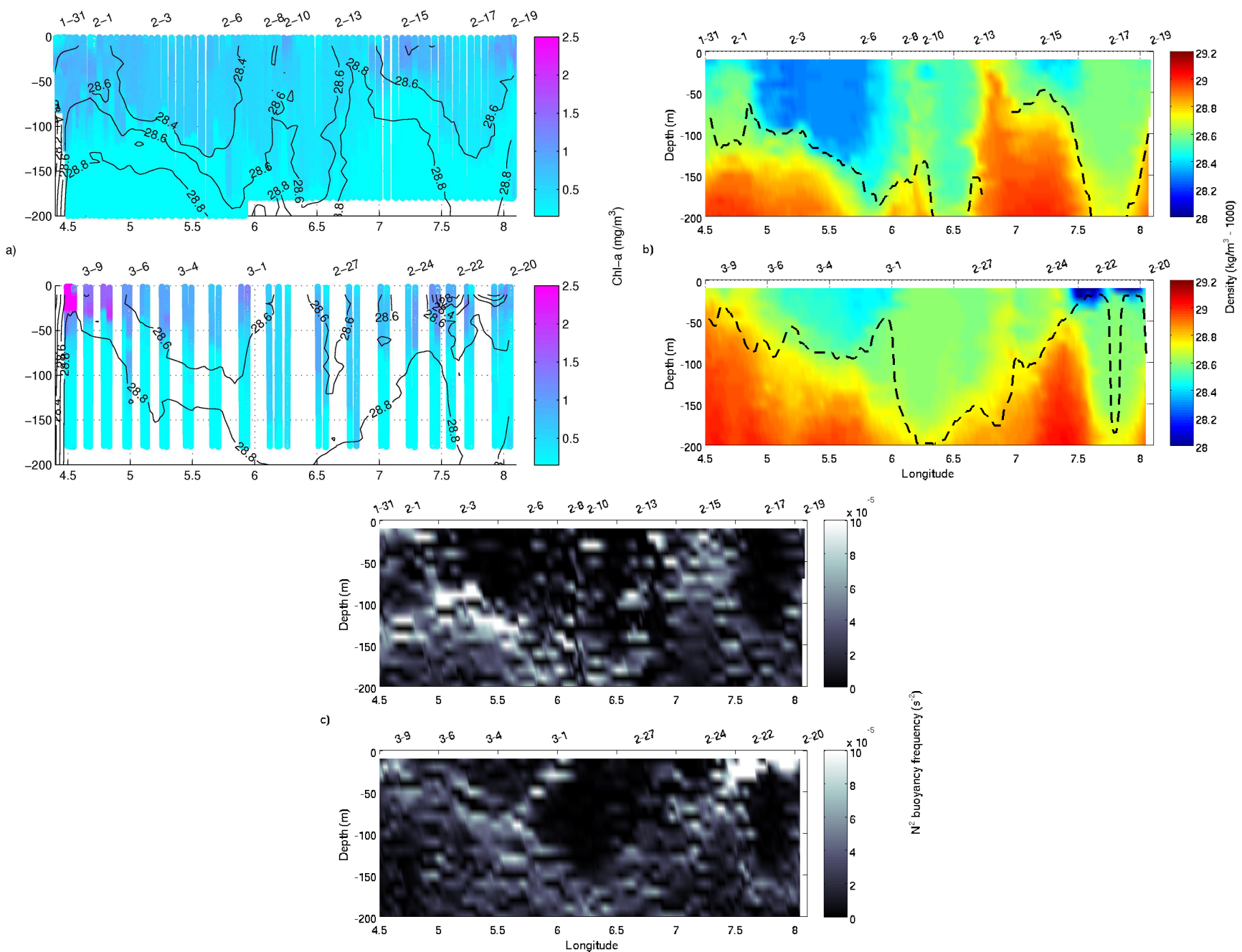

Figure 4. (a) Chlorophyll $a$ sections with superimposed density contours obtained from in situ fluorescence observations for the outbound (upper panels) and return (lower panels) legs of the glider mission. (b) Mixed layer depth (dashed contour line), as calculated from observed densities, superimposed on the density sections of the outbound (upper panels) and return (lower panels) legs of the glider mission; (c) The distribution of the Brunt-Väisälä (buoyancy) frequency $\left(s^{2}\right)$. The panels are provided with dates (MM-DD) to facilitate interpretation.

present study also. Thus, it would seem that heat fluxes are not a very good indicator of bloom onsets on the synoptic scale, even though they can be a useful yardstick for evaluating the shutdown of turbulent convection (Bernardello et al., 2012) on an interannual scale. On the other hand, heat fluxes could be made to work as an effective indicator on all scales provided appropriate lags are introduced. The assumption of a homogeneous distribution of phytoplankton is probably reasonable for the MEDOC area during the pre-stratification period (winter). This would make Sverdrup's CD model still a good choice to study the timing of bloom onsets there. The zeroing of heat fluxes in this case, while reducing turbulent convection, does not automatically imply rapid restratification or bloom initiation, as evidenced by satellite imagery. The MEDOC area shows low levels of Chl $a$ even after the zeroing of heat fluxes supposedly because of a very deep ML, a consequence of the general cyclonic circulation, the intense wind forcing, and occasional water cascading events. According to Taylor and Ferrari (2011a), the rapid re-stratification necessary for premature bloom initiation is facilitated by the presence of water masses of different densities close to each other and dynamical features capable of speeding up such processes. Both these conditions were present along the NBF, which determined the early blooming observed in this study.

It deserves to be noted the occurrence of a south wind event, which peaked around the 4 and 5 March. It probably brought with it an influx of Saharan dust into the area. In fact, MODIS L2 aerosol optical thickness (AOT) products and corresponding quasi-true colour images (not shown) suggest the probable presence of dust in the atmosphere in the pertinent period. The relationship between atmospheric dust 


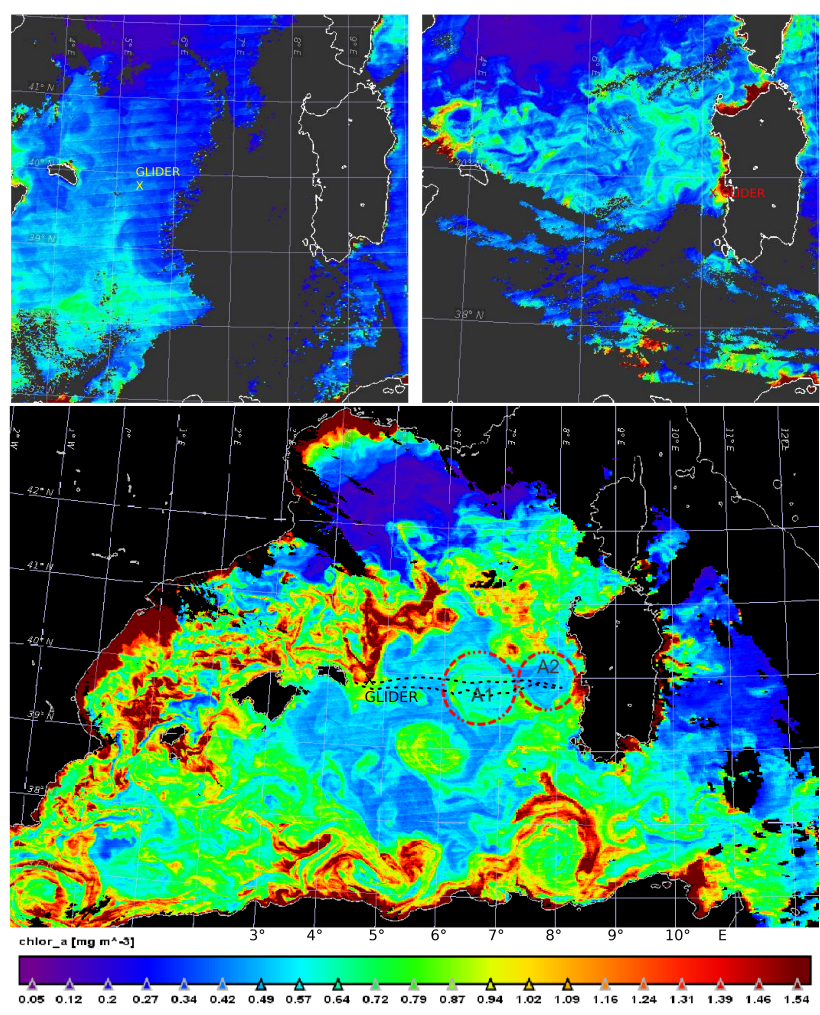

Figure 5. AQUA MODIS chlorophyll a concentrations for: 4 February 2013 (top left), 19 February 2013 (top right), and 8 March 2013 (bottom); the onset of the bloom along the front and near the margins of the big Algerian eddy south of Sardinia is evident in the last image. The glider position is superimposed on each image. Anticyclones crossed by the glider are visible in the last image (A1 and A2).

deposition, which supplies macro- and micro-nutrients, and blooming in the Mediterranean has been investigated in several studies (see Guerzoni et al., 1999, for a review). These studies indicate that, in the northwestern Mediterranean, atmospheric nitrogen and phosphorus inputs could support the production of up to $4 \mathrm{C} \mathrm{m}^{-2} \mathrm{yr}^{-1}$ and $1 \mathrm{Cm}^{-2} \mathrm{yr}^{-1}$, respectively. Although, in the light of some recent estimates (Olita et al., 2011b), this represents only $3-4 \%$ of the total production that has been suggested for the phenomenon to trigger episodic events (Guerzoni et al., 1999).

\section{Summary and conclusions}

The results of the present study show the onset of the phytoplankton bloom in the area where the ML shoals along the NBF between Sardinia and the Balearic Islands. Blooming was triggered by the rapid dynamical re-stratification operated by frontal instabilities after the shutdown of intense wind forcing and the zeroing of heat fluxes (which reduced turbulent convection). An increased input of nutrients in the period prior to the re-stratification can also be presumed given the large vertical velocities that can develop along
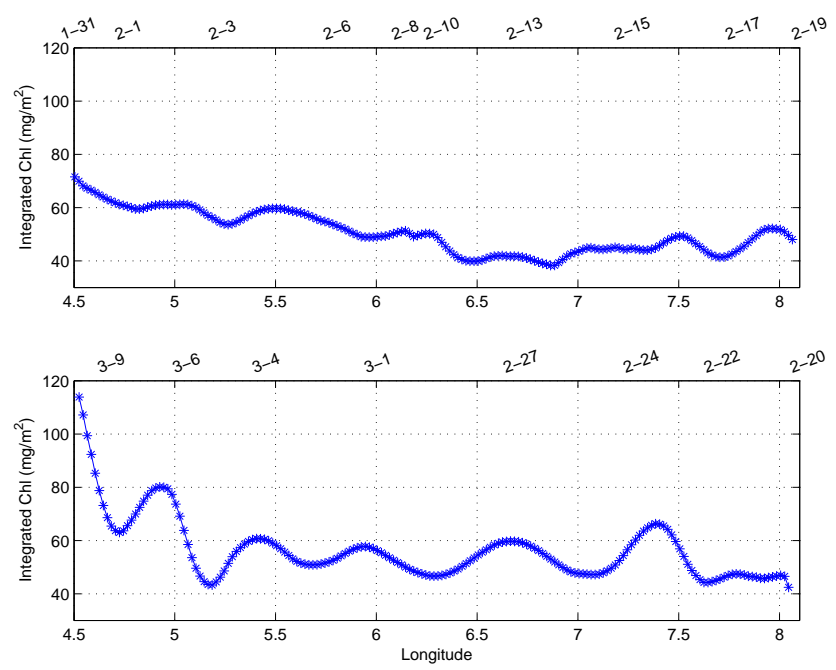

Figure 6. Depth-integrated chlorophyll $a\left(\mathrm{mg} \mathrm{m}^{-2}\right)$ of the first $100 \mathrm{~m}$ of the water column. The upper and lower panels are for the outbound and return legs of the glider mission, respectively. The panels are provided with dates (MM-DD) to facilitate interpretation.

fronts (Tintoré et al., 1991; Viúdez et al., 1996; Lévy et al., 2001; Lévy, 2008; Ruiz et al., 2009; Oguz et al., 2014). The wind forcing, which was very intense and marked by many NW winds (Mistral) events during the whole glider mission, changed direction and began to act from the south towards the end. This contributed to the inversion of the heat fluxes (the sea started to warm up) and the consequent diminution of turbulent convection. Post-storm re-stratification was quicker just across the frontal zone where light waters tended to rapidly overlie denser waters. The re-stratification was enhanced by the instabilities (meanders) of the front itself. This is not the case for areas far from the front. Furthermore, the breakup of the deep stratification in the frontal zone, as shown in Fig. 4, implies a resupply of nutrients to the euphotic layers. This may have also contributed to the onset of the bloom. The analysis conducted suggests that the specific timing of the bloom is strongly related to mesoscale activity associated with the NBF and the margins of the largest anticyclonic eddies that were present.

Some regional insights concerning bloom behaviour were also possible. The satellite image for 9 March and the glider observations clearly show the onset of the early bloom along the NBF and the extremely low concentration of Chl $a$ in the MEDOC area: this is in agreement with previous findings (Olita et al., 2011a, b) showing a delay of about one month between early blooms in the south and subsequent, stronger blooms in the north. Mahadevan et al. (2012) report that blooms in the North Atlantic tend to occur 3-4 weeks before their customary onset time when frontal processes are present. This is on the same order of the lag noted in the northwestern Mediterranean. The asynchrony of the biological response in the different areas of the basin (in spite of 

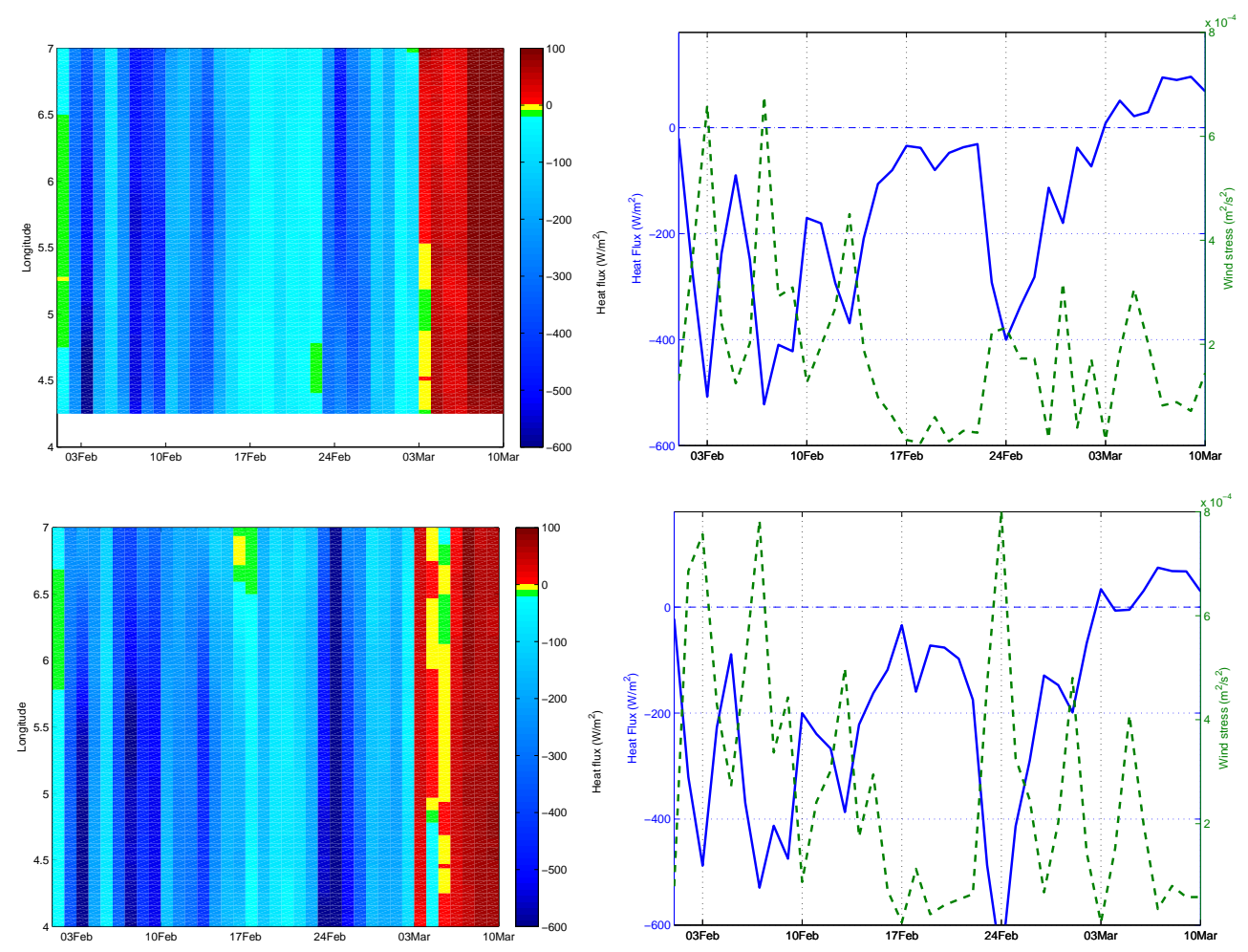

Figure 7. Top panels: Hövmoller diagram of heat fluxes along the glider path on the left, and time series of wind stress and heat fluxes averaged over the area comprising the glider's path on the right. Bottom panels: the same as for the upper panels, but at $42^{\circ} \mathrm{N}$, i.e., north of the front and in the middle of the area of the spring bloom southeast of the Gulf of Lion.

the simultaneous zeroing of heat fluxes) confirms the idea that different processes trigger primary production at different scales and for different areas. In fact, it seems that a shutdown of turbulent convection is effective only where the ML shoals appreciably due to the action of dynamical features. In the deep ML area in the north, where convection is frequent (Schroeder et al., 2008) and involves extensive portions of the water column, there is no immediate biological response to the zeroing of heat fluxes. All the same, the classical CD model should still hold good because the substantial mixing would tend to produce a very homogeneous distribution of phytoplankton in the ML (Chiswell, 2011). In contrast, in the NBF area, the front-enhanced re-stratification mechanism described by Taylor and Ferrari (2011a) seems to be more appropriate.

Many of the above arguments could be verified by implementing a fleet of gliders and covering a wider area. Clarifying the mechanisms regulating the onset of blooms, will lead to a better understanding of phytoplankton dynamics in the Mediterranean, though this will obviously require a thorough investigation of the sub-mesoscale too. The experimental set-up used in this study, which was mainly based on high-resolution, quasi-synoptic sampling of the water column, could be applied to other Mediterranean areas where fronts and their dynamics play an important role not only in fertilizing the upper layer but also in triggering and sustaining the seasonal blooms.

\section{The Supplement related to this article is available online at doi:10.5194/os-10-657-2014-supplement.}

Acknowledgements. The authors thanks the two anonymous reviewers and topic editor Nurit Kress for precious suggestions and corrections.

A. Olita thanks Antonio Donateo for the interesting discussion about atmospheric dust deposition.

The authors also wish to thank Rajesh Nair for English language revision.

The research described in this paper was funded by the European Union's Seventh Framework Programme (FP7/2007-2013) under grant agreement no. 262584, JERICO. The authors especially wish to thank the JERICO TNA program for supporting the GABS (Deep Glider Acquisitions between the Balearic Islands and Sardinia) project which provided much of the data used in this study.

Edited by: N. Kress 


\section{References}

Auger, P., Ulses, C., Estournel, C., Stemmann, L., Somot, S., and Diaz, F.: Interannual control of plankton communities by deep winter mixing and prey/predator interactions in the NW Mediterranean: Results from a 30-year 3D modeling study, Prog. Oceanogr., 124, 12-27, 2014.

Behrenfeld, M. J.: Abandoning Sverdrup's Critical Depth Hypothesis on phytoplankton blooms, Ecology, 91, 977-989, 2010.

Bernardello, R., Cardoso, J. G., Bahamon, N., Donis, D., Marinov, I., and Cruzado, A.: Factors controlling interannual variability of vertical organic matter export and phytoplankton bloom dynamics - a numerical case-study for the NW Mediterranean Sea, Biogeosciences, 9, 4233-4245, doi:10.5194/bg-9-4233-2012, 2012.

Blumberg, A. and Mellor, G.: A description of a three-dimensional coastal ocean circulation model, Coastal Estuarine Science, edited by: Heaps, N. S., Americ. Geophys. Union, Threedimensional Coastal Ocean Models, 1-16, 1987.

Castellari, S., Pinardi, N., and Leaman, K.: A model study of air-sea interaction in the Mediterranean Sea, J. Marine Syst., 18, 89114, 1998.

Chiswell, S. M.: Annual cycles and spring blooms in phytoplankton: Don't abandon Sverdrup completely, Mar. Ecol. Prog. Ser., 443, 39-50, 2011.

Eriksen, C. C., Osse, T. J., Light, R. D., Wen, T., Lehman, T. W., Sabin, P. L., Ballard, J. W., and Chiodi, A. M.: Seaglider: A long-range autonomous underwater vehicle for oceanographic research, IEEE J. Oceanic Eng., 26, 424-436, 2001.

Garau, B., Ruiz, S., Zhang, W. G., Pascual, A., Heslop, E., Kerfoot, J., and Tintoré, J.: Thermal lag correction on slocum CTD glider data, J. Atmos. Ocean. Tech., 28, 1065-1071, 2011.

Guerzoni, S., Chester, R., Dulac, F., Herut, B., Loÿe-Pilot, M. D., Measures, C., Migon, C., Molinaroli, E., Moulin, C., Rossini, P., Saydam, C., Soudine, A., and Ziveri, P.: The role of atmospheric deposition in the biogeochemistry of the Mediterranean Sea, Prog. Oceanogr., 44, 147-190, 1999.

Heslop, E., Ruiz, S., Allen, J., López-Jurado, J., Renault, L., and Tintoré, J.: Autonomous underwater gliders monitoring variability at choke points in our ocean system: A case study in the Western Mediterranean Sea, Geophys. Res. Lett., 39, L20604, doi:10.1029/2012GL053717, 2012.

Huisman, J., van Oostveen, P., and Weissing, F.: Critical depth and critical turbulence: Two different mechanisms for the development of phytoplankton blooms, Limnol. Oceanogr., 44, 1781$1787,1999$.

Lévy, M.: The Modulation of Biological Production by Oceanic Mesoscale Turbulence, in: Transport and Mixing in Geophysical Flows, edited by: Weiss, J. and Provenzale, A., Vol. 744 of Lecture Notes in Physics, 219-261, Springer Berlin/Heidelberg, 2008.

Lévy, M., Klein, P., and Treguier, A.: Impact of sub-mesoscale physics on production and subduction of phytoplankton in an oligotrophic regime, J. Marine Res., 59, 535-565, 2001.

Lévy, M., Ferrari, R., Franks, P. J. S., Martin, A. P., and Rivière, P.: Bringing physics to life at the submesoscale, Geophys. Res. Lett., 39, L14602, doi:10.1029/2012GL052756, 2012.

Mahadevan, A. and Tandon, A.: An analysis of mechanisms for submesoscale vertical motion at ocean fronts, Ocean Model., 14, 241-256, 2006.
Mahadevan, A., D’Asaro, E., Lee, C., and Perry, M. J.: Eddydriven stratification initiates North Atlantic spring phytoplankton blooms, Science, 336, 54-58, 2012.

Martin, A.: The seasonal smorgasbord of the seas, Science, 336, 46-47, 2012.

Millot, C. and Taupier-Letage, I.: Additional evidence of LIW entrainment across the Algerian subbasin by mesoscale eddies and not by a permanent westward flow, Prog. Oceanogr., 66, 231250, doi:10.1016/j.pocean.2004.03.002, 2005.

Oguz, T., Macías, D., and Tintoré, J.: Impacts of boundary current instabilities on plankton production characteristics of the Catalano-Balearic Sea (Western Mediterranean), Ocean Model., submitted, 2014.

Olita, A., Ribotti, A., Sorgente, R., Fazioli, L., and Perilli, A.: SLA - chlorophyll- $a$ variability and covariability in the AlgeroProvençal Basin (1997-2007) through combined use of EOF and wavelet analysis of satellite data, Ocean Dynam., 61, 89-102, doi:10.1007/s10236-010-0344-9, 2011a.

Olita, A., Sorgente, R., Ribotti, A., Fazioli, L., and Perilli, A.: Pelagic primary production in the Algero-Provençal Basin by means of multisensor satellite data: focus on interannual variability and its drivers, Ocean Dynam., 61, 1005-1016, doi:10.1007/s10236-011-0405-8, $2011 \mathrm{~b}$.

Ribotti, A., Puillat, I., Sorgente, R., and Natale, S.: Mesoscale circulation in the surface layer off the southern and western Sardinia Island in 2000-2002, Chem. Ecol., 20, 345-363, 2004.

Rodríguez, J., Tintoré, J., Allen, J., Blanco, J., Gomis, D., Reul, A., Ruiz, J., Rodríguez, V., Echevarría, F., and Jiménez-Gómez, F.: Mesoscale vertical motion and the size structure of phytoplankton in the ocean, Nature, 410, 360-363, 2001.

Ruiz, S., Pascual, A., Garau, B., Pujol, I., and Tintoré, J.: Vertical motion in the upper ocean from glider and altimetry data, Geophys. Res. Lett., 36, L14607, doi:10.1029/2009GL038569, 2009.

Sackmann, B. S., Perry, M. J., and Eriksen, C. C.: Seaglider observations of variability in daytime fluorescence quenching of chlorophyll- $a$ in Northeastern Pacific coastal waters, Biogeosciences Discuss., 5, 2839-2865, doi:10.5194/bgd-5-2839-2008, 2008.

Schroeder, K., Ribotti, A., Borghini, M., Sorgente, R., Perilli, A., and Gasparini, G. P.: An extensive western Mediterranean deep water renewal between 2004 and 2006, Geophys. Res. Lett., 35, 18605, doi:10.1029/2008GL035146, 2008.

Sverdrup, H.: On conditions for the vernal blooming of phytoplankton, J. Cons. Int. Explor. Mer, 18, 287-295, 1953.

Taylor, J. R. and Ferrari, R.: Ocean fronts trigger high latitude phytoplankton blooms, Geophys. Res. Lett., 38, L23601, doi:10.1029/2011GL049312, 2011a.

Taylor, J. R. and Ferrari, R.: Shutdown of turbulent convection as a new criterion for the onset of spring phytoplankton blooms, Limnol. Oceanogr., 56, 2293-2307, doi:10.4319/lo.2011.56.6.2293, $2011 b$.

Tintoré, J., Gomis, D., Alonso, S., and Parrilla, G.: Mesoscale Dynamics and Vertical Motion in the Alborán Sea, J. Phys. Oceanogr., 21, 811-823, 1991.

Tintoré, J., Casas, B., Heslop, E., Vizoso, G., Pascual, A., Orfila, A., Ruiz, S., Renault, L., Juzà, M., Balaguer, P., GómezPujol, L., Álvarez-Ellacuria, A., Gómara, S., Sebastian, K., Lora, S., Beltrán, J., March, D., Escudier, R., Martínez-Ledesma, M., Torner, M., Cusí, S., Roque, D., Lizarán, I., Castilla, C., Cañel- 
las, T., Lana, A., Conti, D., Sayol, J., Mason, E., Barceló-Llull, B., Alemany, F., Álvarez-Berastegui, D., Reglero, P., Massuti, E., Vélez-Belchí, P., Ruiz, J., Oguz, T., Gómez, M., Álvarez, E., Ansorena, L., and Manriquez, M.: The impact of new multiplatform observing systems in science, technology development and response to society needs; From small to large scales., Lecture Notes in Computer Science (including subseries Lecture Notes in Artificial Intelligence and Lecture Notes in Bioinformatics), 8112 LNCS, 341-348, 2013.
Viúdez, Á., Haney, R., and Tintoré, J.: Circulation in the Alboran Sea as determined by quasi-synoptic hydrographic observations. Part II: Mesoscale ageostrophic motion diagnosed through density dynamical assimilation, J. Phys. Oceanogr., 26, 706-724, 1996. 